Rev. Estud. Ling., Belo Horizonte, v. 27, n. 1, p. 213-240, 2019

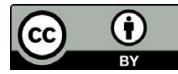

\title{
Efeito de treinamento de memória de trabalho em crianças sem diagnósticos de comprometimento cognitivo, estudantes das séries iniciais do Ensino Fundamental
}

\section{Working Memory Training Effect in Elementary School Children Without Diagnosis of Cognitive Impairment}

\author{
Lidiomar José Mascarello \\ Rede Municipal de Florianópolis, Florianópolis, Santa Catarina / Brasil \\ lidiomarjose@gmail.com
}

Resumo: O propósito principal deste artigo é apresentar resultados de pesquisas que mostram a relevância de um treinamento da memória de trabalho em crianças sem diagnóstico de déficit de atenção ou outras complicações cognitivas. São crianças estudantes do segundo ano do Ensino Fundamental em processo inicial de aprendizagem de leitura e escrita. Participaram do estudo 165 sujeitos. Todos os participantes foram submetidos a pré e pós testes que avaliaram índices de memória de trabalho e desempenho em leitura silenciosa de palavras e pseudopalavras. Além da apresentação dos resultados objetivamos discutir questões referentes a estudos da memória de trabalho (MT) e suas implicações nos processos de aprendizagem de leitura. Os resultados das pesquisas indicam que crianças com maior capacidade de memória de trabalho apresentam melhor desempenho em tarefas de leitura que crianças com menor capacidade nessa memória, tais resultados são consonantes a outros estudos na área.

Palavras-chave: memória de trabalho; efeito de treinamento; leitura.

Abstract: This study aims to present research results that show the relevance of work memory training in children without a diagnosis of attention deficit or other cognitive complications. They are children of the second year of the Elementary School in the initial process of learning to read and write. 165 subjects participated in the study. All participants were submitted to pre and post tests that evaluated work memory indices and performance in silent word and pseudoword reading. In addition to the presentation of the results, we aimed to discuss issues related to working memory (TM) studies and 
their implications for reading learning processes. The results of research indicate that children with higher working memory capacity perform better on reading tasks than children with lower memory capacity, such results are consonant with other studies in the area.

Keywords: working memory; training effect; reading.

Recebido em 08 de maio de 2018 Aceito em 04 de setembro de 2018

\section{Introdução}

O estudo da memória humana é uma área de pesquisa que a psicologia cognitiva investiga há muito tempo. Um dos estudos mais antigos que se tem registro é o de Ebbinghaus em 1885 (apud BADDELEY et al., 2011, p. 83). Entretanto até hoje não é um campo em que há consenso sobre a conceituação e a definição do que é memória humana. Para autores como, por exemplo, Kandel (2009), a memória é a capacidade de reportar-se às lembranças e reminiscências registradas em nosso cérebro. Em outras palavras, podemos dizer que a memória é a capacidade humana de registrar, conservar e relembrar mentalmente experiências de vida, conhecimentos, conceitos, sensações e pensamentos experimentados no decorrer do percurso da vida. Contudo, defender tal ponto de vista implica fazer escolhas teóricas priorizando uma em relação a outras.

Baddeley et al. (2011, p.14) defendem que a partir de novos estudos da Neurobiologia e da Psicologia Cognitiva, é possível falar de memórias e não apenas de memória como se fosse um sistema simples e único. O mesmo autor argumenta que, de fato, existem várias memórias, isto é, vários sistemas de memórias, pois há diversas fontes de armazenamento de dados em nossa mente, não limitadas em uma área determinada de nosso cérebro, mas inerentes a distintas atividades mentais (BADDELEY, et al., 2011).

Assim como não há consenso na formulação de um conceito único sobre memória humana também não é tarefa simples determinar quais são os tipos de memória existentes e como devem ser identificados. Existem, na literatura sobre o tema, várias formas e sistemas classificatórios, sendo que alguns priorizam o sistema de funcionamento da memória, outros 
a temporalidade, ou seja, o tempo de armazenamento da informação na mente humana, dentre outras formas e critérios para classificá-la (PURVES et al., 2004). Em comum, as diferentes linhas teóricas concordam que a memória é o funcionamento articulado de vários sistemas cerebrais responsáveis pelo registro e armazenamento de informações (por um período de tempo) que podem ser recuperadas (KANDEL, 2009).

Para Baddeley et al. (2011), a memória humana está organizada em memória sensorial, memória de curto prazo, memória de trabalho e memória de longo prazo, definições nas quais me apoiei para a realização do estudo.

A memória sensorial tem importância primordial que nos possibilita reconhecer padrões em gral, também conhecido como padrão sensorial. É um sistema de memória que através da percepção da realidade, pelos órgãos do sentido, retém por alguns segundos a imagem detalhada da informação sensorial recebida. Ela é responsável pelo processamento inicial da informação sensorial e sua codificação (BARKLEY, BENTON, 2011). A relação bem sucedida entre os órgãos do sentido e o cérebro é de extrema importância para a memória, segundo Barkley, Benton (2011) a memória não entra em ação só quando tentamos recordar algo, mas ela é um processo em constante construção e o nosso comportamento pode estimula-la ou não.

Em relação à memória de curto prazo nos referimos à retenção temporária de pequenas quantidades de material por um breve período de tempo. Segundo Baddeley (2011, et al., p.31), [...] "é um sistema de memória responsável por receber as informações e retê-las por um curto período de tempo". As informações aí retidas são as provenientes de qualquer órgão do sentido. A memória de curto prazo é responsável pela triagem das informações recebidas para que estas sejam utilizadas, descartadas ou mesmo organizadas para serem armazenadas.

A memória de longo prazo ou longa duração é o sistema de memória que recebe as informações da memória de curta duração e as armazena por longos períodos de tempo. Para Baddeley et al. (2011), caso não haja danos cerebrais, o armazenamento pode ser por um prazo indeterminado, pois é uma memória considerada de capacidade ilimitada de armazenamento e, as informações ficam nela armazenadas por tempo também ilimitado.

Em linhas gerais, a memória humana é constituída pela capacidade dos seres humanos de adquirir, conservar e evocar informações através de 
dispositivos neurobiológicos e da interação social (BADDELEY, 1992). A memória é constituída de um conjunto de procedimentos que permite manipular e compreender o mundo, levando em conta o contexto atual e as experiências individuais, recriando esse mundo por meio de ações pessoais/individuais (BADDELEY, 1992).

Em 1974, Baddeley e Hitch, ao estudarem os modelos de memória apresentados até então, constatam e demonstram por meio de novas pesquisas, que os modelos antecedentes, em especial o modelo de Atkinson e Schiffrin (1968) não consegue explicar uma série de fenômenos cognitivos e evidências neuropsicológicas. Com isso, Baddeley e Hitch (1974) propõem um novo modelo, denominado Modelo Multicomponencial. Baddeley e Hitch (1974) passam a defender a ideia de que além da memória de curto e de longo prazo existe uma memória capaz de manipular informações, isto é, uma memória de trabalho, um sistema temporário (de curta duração) que é capaz de operar, processar e manter informações na mente por um curto espaço de tempo. Esse novo modelo é composto inicialmente por três partes ou componentes de memória de trabalho: 1 - Circuito Fonológico; 2 - Bloco de Espaço Visuoespacial; e 3 - Executivo central. De acordo com este novo modelo, a Alça Fonológica é basicamente um componente de memória verbal de curta duração responsável pelos aspectos linguísticos nos processamentos cognitivos, aspectos relacionados desde a codificação semântica, articulação das palavras, estruturação e até aprendizagem de novas línguas. O Esboço Visuoespacial é o componente responsável pela manutenção temporária de informações visuais e espaciais. $\mathrm{O}$ componente Executivo Central é o gerenciador dos dois subsistemas Alça Fonológica e Esboço Visuoespacial articulando também a memória de longo prazo. Segundo Baddeley et al. (2011), o circuito fonológico é uma parte específica da memória de trabalho e pode ser considerado como um subsistema específico desta memória. O circuito fonológico ou alça fonológica é a parte da memória de trabalho que lida com informações provenientes de material escrito e falado. Ela pode ser usada para lembrar um número de telefone, por exemplo, e está organizada em duas partes principais. A primeira parte principal é o compartimento fonológico (ouvido interna), que está vinculado à percepção de fala e que, baseando-se no discurso, apresenta informações de forma (ou seja, palavras faladas) por 1-2 segundos. A outra parte é o processo de controle articulatório, (voz interior) e está ligada à produção da fala. O processo 
de controle articulatório é utilizado para armazenar informações verbais do compartimento fonológico.

O circuito ou alça visuoespacial lida com informação visual e espacial. Informação visual se refere ao que as coisas se parecem ou são no mundo real. É provável que esboço visuoespacial tem um papel importante para nos ajudar a manter o controle de onde estamos em relação a outros objetos, como nós nos movemos no meio em que vivemos (BADDELEY, et al., 2011).

À medida que nos movimentamos, a nossa posição em relação aos objetos se modifica e é importante que possamos manter essas informações atualizadas: por exemplo, ter consciência de onde estamos em relação às mesas e cadeiras em uma sala de aula permite que não esbarremos nelas. Este circuito nos permite também resgatar informações visuais e espaciais da memória de longo prazo.

O componente executivo central é o componente mais importante do modelo, embora não se tenha conhecimento completo sobre seu funcionamento e ainda estão sendo realizadas pesquisas para compreender melhor as suas características funcionais. De acordo com Baddeley et al. (2011), este componente é responsável pelo acompanhamento e coordenação da operação dos sistemas visuoespacial e circuito fonológico e os relaciona com a memória de longo prazo. O componente executivo central decide quais informações são atendidas e quais partes da memória de trabalho enviarão essa informação para ser executada.

O componente executivo central é responsável por controlar o foco de atenção do indivíduo. O executivo central decide em que a pessoa, por meio do componente cognitivo memória de trabalho, presta atenção. Por exemplo, duas atividades às vezes entram em conflito, tais como dirigir um carro e conversar. Ao invés de atropelar um ciclista que está andando a sua frente, é preferível parar de falar e se concentrar na condução. $\mathrm{O}$ componente executivo central dirige a atenção e dá prioridade a atividades particulares. O componente executivo central é o componente mais versátil e importante do sistema de memória de trabalho.

Baddeley et al. (2011) sugere que o componente executivo central age mais como um sistema que controla os processos de atenção e não como um armazenamento de memória. Isso é diferente da alça fonológica e a alça visuoespacial, que são sistemas de processamento especializados. O componente executivo central permite que o sistema de memória de trabalho seja seletivo. 
Baddeley et al. (2011) usa a metáfora de um chefe de empresa para descrever o funcionamento do executivo central. $O$ chefe da empresa toma decisões sobre questões que merecem atenção e o que deve ser ignorado. Ele também seleciona estratégias para lidar com problemas, mas como qualquer pessoa na empresa, o patrão só pode fazer um número limitado de coisas ao mesmo tempo.

Como podemos observar, nesse novo modelo, a memória de curta duração deixa de ser um arquivo passivo, isto é, deixa de ser apenas um receptor de informações, um lugar em que apenas se guarda algo, para ser um local de trabalho em que a matéria/informação aí colocada está constantemente sendo manipulada, (re)combinada e transformada. Além disso, esse local de trabalho, esse espaço cerebral, contém tanto material novo/informação nova que chega do ambiente quanto material antigo/ memórias já anteriormente guardadas extraído da memória de longo prazo (BADDELEY, et al., 2011).

Por apresentar essas características, muitas são as pesquisas que buscam identificar relações entre aspectos da linguagem considerados essenciais para a aprendizagem de leitura e dos sub processos necessários para a concretização do ato de ler e a memória de trabalho. Os pesquisadores das áreas cognitivas (neurolinguística, neuropsicologia, etc.) e psicolinguística concordam que a memória de trabalho é indispensável para o sucesso e bom desempenho em tarefas cognitivas. Embora haja essa concordância, não é consenso entre os estudiosos que é possível melhorar os índices dessa memória. Para alguns pesquisadores, a MT pode ser expandida, mas para outros não. Outra divergência gerada a partir desse posicionamento é a possibilidade de generalizar que, ao melhorar a MT, melhora-se consequentemente o desempenho em tarefas cognitivas. Tal posicionamento se dá pelo fato de os estudos serem julgados muito recentes e apresentarem dados considerados inconsistentes para comprovar essas evidências (segundo os pesquisadores que defendem que os índices da MT não podem ser melhorados). Tal posicionamento é adotado, por exemplo, pelo grupo de pesquisadores do Georgia Institute of Technology, sob a coordenação do Dr. Randall Engle, estuda Attention and Working Memory. ${ }^{1}$ Em estudo

\footnotetext{
${ }^{1}$ Outras informações sobre tal posicionamento podem ser encontradas no site $<$ http:// englelab.gatech.edu/publications.html\#2010-Present>. Nesse endereço são encontradas as principais publicações desse grupo de pesquisa.
} 
publicado em 2010, por exemplo, afirmam que não é possível ampliar a MT por treinamento adaptado e pela execução de tarefas, mas que as diferenças nos índices podem ocorrer a partir das diferenças individuais entre os sujeitos ou por falta de controle adequado nas variáveis cognitivas envolvidas no processo (SHIPSTEAD, 2010).

Em contrapartida, grupos como o da Universiy of York que também estudam Working Memory and Attention, Language, and Learning, coordenados pela Dra. Susan Gathercole, defendem que programas de treinamento cognitivo podem ser aplicados como forma de intervenção para minimizar problemas de atenção e melhorar a MT (HOLMES; GATHERCOLE; DUNNING, 2009). E também do Departamento de Neuropediatria do Karolinska Institute, coordenado pelo Dr. Torkel Klingberg, ao estudarem crianças com dificuldades e deficit de atenção e MT, defendem que é possível melhorar os índices de MT. E o resultado da melhoria influencia também os resultados em outras atividades cognitivas como, a diminuição do tempo na execução de tarefas motoras em crianças com TDAH (KLINGBERG et al., 2002; KLINGBERG et al., 2005; SWANSON; SACHSE-LEE, 2001). ${ }^{2}$

Mesmo diante de divergências, pensamos que a MT pode ser melhorada. E por pensarmos dessa forma, filiamo-nos ao grupo que defende que, a partir de treinamento específico, a memória de trabalho pode ser expandida dentro de um limite e de um contexto. A MT, como elemento essencial da nossa cognição, ganhou ampla aceitação como principal indicador do desempenho acadêmico, profissional e pessoal, (GATHERCOLE; PICKERING, 2000). E, depois de anos de estudos, evidências dos resultados de pesquisas e sucesso clínico, efetuados também pelos dois polos de estudos há pouco referenciados, acreditamos que o treinamento para aumentar a capacidade de MT é considerado como um avanço nas pesquisas.

Programas de treinamento cognitivo são aceitos como uma forma de intervenção para minimizar problemas de atenção (HOLMES; GATHERCOLE; DUNNING, 2009). Os programas são baseados em um conceito chamado "formação da memória de trabalho". Em relação ao conceito de memória de trabalho adotamos o defendido como "o modelo

\footnotetext{
${ }^{2}$ Outras informações sobre tal posicionamento podem ser encontradas nas publicações no site: <https://pure.york.ac.uk/portal/en/researchers/susan-e-gathercole(21f554a609c5-4b57-a3a3-d1b870d90be1)/publications.html>.
} 
multicomponencial" (BADDELEY, HITCH, 1974) e suas atualizações. Os autores defendem que na verdade a memória de curto prazo constituise de uma parte compreendida como uma memória de trabalho, isto é, um sistema temporário (também de curta duração) que é capaz de manipular, processar e manter informações na mente por um curto espaço de tempo (BADDELEY, 2003).

Em relação ao aspecto da leitura, ou ao ato de ler, pode ser compreendido e estudado sob diferentes aspectos, pois, em algum modo, é polimorfo, isto é, o ato de ler pode ser entendido e apresentado de diversas formas e por diferentes perspectivas teóricas. Como já foi defendido em Mascarello (2016, p 69) "o estudo aqui apresentado está vinculado e relaciona-se com os diversos estudos que têm como fio condutor a visão de leitura como um processo cognitivo complexo, não resumido a um produto final a ser analisado". Nesse sentido, parece-nos coerente que são necessários ou fazem parte do processo das operações cognitivas interligadas, os movimentos ascendentes e descendentes (que envolvem aspectos informativos tanto do texto quanto da experiência do leitor) situados no tempo e no espaço em constante interação. A leitura não é o produto simples da soma das contribuições do leitor e do texto. Além desses dois aspectos muito importantes, é preciso considerar também um terceiro elemento: o resultado proporcionado pelo encontro do leitor com o texto. Para compreender o ato da leitura, temos que considerar então "(a) o papel do leitor, (b) o papel do texto e (c) o processo de interação entre o leitor e o texto" (LEFFA, 1996, p. 17).

Diante dessa possibilidade, de extrair e atribuir significados de um texto, surgem pelo menos duas ações ou dois modos de posicionamento diante do ato de ler: um que prioriza os aspectos e processos cognitivos e entende que a leitura é um processo cognitivo; e outro que prioriza os aspectos e os efeitos sociais ou de socialização que a leitura possibilita, entendendo que a leitura é uma prática social.

$\mathrm{Na}$ perspectiva das teorias que priorizam os aspectos cognitivos, em diferentes áreas de estudos, entre elas a área da psicolinguística, alguns autores que estudam aprendizagem de leitura, por exemplo, Gough (1976), Souza (2004), Gathercole e Alloway (2006), Scliar-Cabral e Souza (2011), Souza e Garcia (2012) enfatizam mais os aspectos referentes ao processamento da informação que os benefícios sociais da leitura.

Trabalhamos com três hipóteses: 
(1) Há relação entre a capacidade de memória de trabalho e o desempenho em leitura de crianças com idade entre 07 e 09 anos em processo de alfabetização, sendo que, crianças com maior capacidade de memória de trabalho apresentam melhor desempenho em tarefas de leitura que crianças com menor capacidade nessa memória;

(2) A capacidade da memória de trabalho de crianças com desempenho baixo em leitura pode ser aumentada através de intervenção específica;

(3) A expansão da capacidade de memória de trabalho de crianças com baixo desempenho em leitura tem efeitos positivos sobre esse desempenho acadêmico (MASCARELLO, 2016, p. 28,29).

Em nosso estudo buscamos respostas para as perguntas:

1) Existe relação entre memória de trabalho e os processos cognitivos de decodificação e compreensão envolvidos na aprendizagem da leitura por crianças em processo de alfabetização na faixa etária de 07 a 09 anos de idade?

2) Se existe relação entre memória de trabalho e os processos cognitivos de decodificação e compreensão envolvidos na aprendizagem de leitura, crianças com baixo índice de memória de trabalho apresentam menor rendimento e maior dificuldade no processo de aprendizagem de leitura?

3) É possível melhorar, isto é, aumentar os índices de memória de trabalho através de intervenção específica para além do aumento considerado naturall que ocorre nesta faixa etária?

4) Qual é o efeito de uma intervenção específica que objetiva melhorar a capacidade da memória de trabalho em crianças da faixa etária 07 a 09 anos sobre o desempenho em leitura?

5) A expansão da memória de trabalho tem efeito positivo sobre o desempenho em leitura? (MASCARELLO, 2016, p. 28).

Na sequência do texto apresentamos os aspectos metodológicos, a análise dos dados e resultados obtidos no estudo. 


\section{Método}

\subsection{Participantes}

Para realizar o estudo foram adotadas algumas estratégias procedimentais, a saber: aplicação de um conjunto de testes com o intuito de avaliar a memória de trabalho e também testes para verificar estratégias e rotas de leitura. Foram executados pré e pós testes, intercalados por um período de intercessão de 10 semanas com o grupo experimental. Participaram da pesquisa 165 sujeitos, sendo $\mathrm{n}=165$. A média de idade dos 165 participantes foi de 7,3 anos no pré-teste e 7,7 anos no pós-teste, 76 participantes são do sexo masculino e 89 são do sexo feminino. Todos os participantes são estudantes do segundo ano do Ensino Fundamental. O local da coleta de dados foi em uma escola da rede estadual de ensino, localizada em Florianópolis, SC.

\subsection{Instrumentos}

Os sujeitos que participaram e colaboraram com o estudo foram investigados e submetidos a tarefas que mediram seu desempenho e capacidade de leitura a partir do Teste de Competência de Leitura de Palavras e Pseudopalavras (TCLPP) (SEABRA; CAPOVILLA, 2010). ${ }^{3}$ Esse teste avalia a competência de leitura de itens escritos individuais e analisa processos de leitura em suas três vertentes: os processos ideovisuais logográficos, típicos do rudimentar estágio logográfico de leitura por reconhecimento primário e desprovido de qualquer decodificação; os processos perilexicais de decodificação grafêmica, típicos do estágio de leitura alfabético, e os processos lexicais de reconhecimento visual direto de formas ortográficas familiares, típicos do estágio ortográfico e sempre acompanhados da capacidade de decodificação já instalada (CAPOVILLA; CAPOVILLA; MACEDO, 2005; CAPOVILLA; CAPOVILLA; MACEDO, 2006).

O TCLPP contém 70 itens, sendo dez itens para cada um dos sete subtestes distribuídos em ordem aleatória, isto é, não são apresentadas

\footnotetext{
${ }^{3}$ Estamos cientes de que tanto os testes de memória quanto os de leitura de palavras utilizados são passíveis de observações e críticas e que leitura não se limita a reconhecer e compreender palavras, mas os instrumentos foram julgados adequados considerando a idade e a escolaridade dos sujeitos e os objetivos do estudo.
} 
na sequência as 10 palavras corretas regulares, as 10 palavras corretas irregulares, etc. A pontuação máxima é de 70 pontos. Como há duas respostas possíveis para cada item, a pontuação casual é de 35 pontos brutos no total do teste e de 5 pontos brutos em cada subteste. Cada item é composto de uma figura e um elemento escrito. O participante deverá, ao realizar o teste, circular os itens corretos e cruzar com " $X$ " os incorretos.

Há dois subtestes com itens corretos:

- Palavras corretas regulares (CR) (ex. FADA sob a figura de uma fada) e

- Palavras corretas irregulares (CI) (ex. TÁXI sob a figura de um táxi).

Há cinco subtestes compostos de itens incorretos:

1. Palavras semanticamente incorretas, que diferem das figuras às quais estão associadas, ou seja, vizinhas semânticas (VS) (ex., palavra GATO sob a figura de cão);

2. Pseudopalavras estranhas (PE) (ex., MELOCE sob figura de palhaço);

3. Pseudopalavras homófonas (PH) (ex., JÊNIU sob a figura de gênio);

4. Pseudopalavras pseudo-homófonas com trocas fonológicas, ou seja, vizinhas fonológicas (VF) (ex., MÁCHICO sob a figura de mágico) e

5. Pseudopalavras pseudo-homógrafas com trocas visuais, ou seja, vizinhas visuais (VV) (ex. TEIEUISÃO sob a figura de televisão).

Para coletar os dados referentes à memória de trabalho utilizaramse os subtestes de memória da Escala Wechsler de Inteligência para Crianças (WISC-IV, 2013). Essa escala é considerada um instrumento clínico de aplicação individual, utilizado para avaliar a "capacidade intelectual e o processo de resolução de problemas em crianças entre 6 anos e 0 mês a 16 anos e 11 meses" (WECHSLER, 2013, p. 1).

De acordo com o manual de instruções e o manual técnico, essa escala de avaliação é composta por quatro grupos de atividades chamados de índices. Cada índice avalia aspectos diferentes de elementos constitutivos da cognição humana, a saber: 
a) Índice de Compreensão Verbal (ICV);

b) Índice de Organização Perceptual (IOP);

c) Índice de Memória Operacional (IMO); e

d) Índice de Velocidade de Processamento (IVP).

O ICV é formado por subtestes que se "destinam à aferição das habilidades verbais por meio do raciocínio, da compreensão e da conceituação" (WECHSLER, 2013, p. 2). O IOP, índice de organização perceptual, mede a capacidade que o sujeito tem de se organizar e perceber seu contexto. O IMO, índice de memória operacional, avalia capacidade de atenção e concentração e a memória de trabalho em geral. O IVP, índice de velocidade de processamento, aponta índices de agilidade mental e processamento grafomotor. A bateria de testes WISC - IV é composta em sua totalidade por 15 subtestes, sendo 10 principais e 5 suplementares. Para a aferição da memória de trabalho foi feito uso dos testes Ordem Direta e Ordem inversa de números, Sequência de Números e Letras e Aritmética da Escala Wechsler Intelligence Scale for Children - WISC IV - para medir memória de trabalho. Os testes avaliam aspectos da memória de trabalho auditiva e visual, discriminação fonológica e a capacidade de manter e processar informações.

\subsection{Procedimentos}

Os sujeitos foram divididos em 5 sub grupos. A divisão ocorreu a partir dos resultados dos dados dos pré-testes comparados aos valores da padronização estabelecidos pelos mesmos, sendo:

1) Experimental (31 participantes, os que obtiveram baixos índices nos testes de memória de trabalho e no teste de competência de leitura de palavras e pseudopalavras);

2) Controle (28 participantes, os que obtiveram baixos índices nos testes de memória de trabalho e no teste de competência de leitura de palavras e pseudopalavras);

3) Regular (56 participantes, os que obtiveram índices considerados dentro da normalidade padrão de acordo com idade e ano escolar nos testes de memória de trabalho e no teste de competência de leitura de palavras e pseudopalavras); 
4) WmpobreLn ${ }^{4}$ (27 participantes, os que obtiveram baixos índices nos testes de memória de trabalho e índices normais no teste de competência de leitura de palavras e pseudopalavras);

5) LpobreWMn ${ }^{5}$ (23 participantes, os que obtiveram baixos índices no teste de competência de leitura de palavras e pseudopalavras e índices normais nos testes de memória de trabalho) (MASCARELLO, 2016, p.94).

A intervenção, para o grupo experimental, foi realizada a partir da utilização de um protocolo de intervenção constituído por 17 jogos com tarefas distintas. Os jogos foram aplicados alternadamente durante um período de 10 semanas. A duração foi de 35 minutos diários, repetidos 5 vezes na semana. Aqui o leitor pode perguntar-se: por que 35 minutos? É que em uma aula de 50 minutos só conseguíamos efetivamente trabalhar com as atividades por cerca de 35 minutos, o tempo restante da hora aula era ocupado com deslocamento dos estudantes e com a organização dos grupos na sala de atividades. Os alunos do grupo experimental eram deslocados de suas salas de aula para uma sala específica. A sala era previamente organizada e preparada para a realização das atividades. Os demais alunos, dos outros grupos, permaneciam em suas salas de aula realizando atividades de rotina. As atividades do grupo experimental sempre eram realizadas na primeira aula do período vespertino. Alguns desses jogos foram adaptados a partir de jogos de memória disponíveis online e outros foram jogos criados anteriormente por outros pesquisadores, ou ainda, jogos clássicos utilizados e adaptados para a aprendizagem em sala de aula. Os jogos respeitam os aspectos visuoespaciais, verbais, numérico-verbais e verbais e visuoespaciais ao mesmo tempo.

\subsection{Protocolo de intervenção}

Nas Tabelas abaixo visualizam-se atividades propostas no protocolo de intervenção com características, domínios e com a ordem de realização das atividades.

\footnotetext{
${ }^{4}$ A abreviação WmpobreLn significa memória de trabalho pobre e leitura normal.

${ }^{5}$ A abreviação LpobreWMn significa leitura pobre e memória de trabalho normal.
} 


\section{TABELA 01 - Tabela referente ao protocolo de intervenção}

\begin{tabular}{|c|c|c|c|c|c|}
\hline Atividade & Tarefa & Objetivo & $\begin{array}{c}\text { Habilidade } \\
\text { requerida }\end{array}$ & Material & Domínio \\
\hline Dominó & $\begin{array}{l}\text { Aprender as } \\
\text { regras e jogar } \\
\text { dominó }\end{array}$ & $\begin{array}{l}\text { Treinar habilidade } \\
\text { de atenção, } \\
\text { flexibilidade } \\
\text { cognitiva }\end{array}$ & $\begin{array}{c}\text { Atenção } \\
\text { difusa, atenção } \\
\text { concentrada, } \\
\text { percepção visual }\end{array}$ & $\begin{array}{l}\text { Dominó } \\
\text { tradicional } \\
\text { colorido }\end{array}$ & $\begin{array}{l}\text { Visuoespacial, } \\
\text { articulado pelo } \\
\text { executivo central }\end{array}$ \\
\hline $\begin{array}{l}\text { Dominó } \\
\text { Adição }\end{array}$ & $\begin{array}{l}\text { Encontrar o } \\
\text { resultado da } \\
\text { soma indicada }\end{array}$ & $\begin{array}{l}\text { Treinar habilidade } \\
\text { de atenção, } \\
\text { memória, } \\
\text { pensamento lógico }\end{array}$ & $\begin{array}{c}\text { Atenção } \\
\text { difusa, atenção } \\
\text { concentrada, } \\
\text { memória de } \\
\text { trabalho }\end{array}$ & $\begin{array}{c}\text { Dominó feito } \\
\text { em papel cartão, } \\
\text { (adaptado para } \\
\text { idade e ano } \\
\text { escolar) }\end{array}$ & $\begin{array}{c}\text { Memória } \\
\text { visuoespacial e } \\
\text { atenção; executivo } \\
\text { central }\end{array}$ \\
\hline $\begin{array}{l}\text { Dominó } \\
\text { Subtração }\end{array}$ & $\begin{array}{l}\text { Encontrar } \\
\text { o resultado } \\
\text { da subtração } \\
\text { indicada }\end{array}$ & $\begin{array}{l}\text { Treinar habilidade } \\
\text { de atenção, } \\
\text { memória, } \\
\text { pensamento lógico }\end{array}$ & $\begin{array}{c}\text { Atenção } \\
\text { difusa, atenção } \\
\text { concentrada, } \\
\text { memória } \\
\text { de trabalho, } \\
\text { raciocínio lógico }\end{array}$ & $\begin{array}{l}\text { Dominó feito } \\
\text { em papel-cartão, } \\
\text { (adaptado para } \\
\text { idade e ano } \\
\text { escolar) }\end{array}$ & $\begin{array}{c}\text { Memória } \\
\text { visuoespacial e } \\
\text { atenção; executivo } \\
\text { central }\end{array}$ \\
\hline $\begin{array}{c}\text { Dominó } \\
\text { Multiplicação }\end{array}$ & $\begin{array}{l}\text { Encontrar o } \\
\text { resultado da } \\
\text { multiplicação } \\
\text { indicada }\end{array}$ & $\begin{array}{l}\text { Treinar habilidade } \\
\text { de atenção, } \\
\text { memória, } \\
\text { pensamento lógico }\end{array}$ & $\begin{array}{c}\text { Atenção } \\
\text { difusa, atenção } \\
\text { concentrada, } \\
\text { memória } \\
\text { de trabalho, } \\
\text { raciocínio lógico }\end{array}$ & $\begin{array}{l}\text { Dominó feito } \\
\text { em papel-cartão, } \\
\text { (adaptado para } \\
\text { idade e ano } \\
\text { escolar) }\end{array}$ & $\begin{array}{c}\text { Memória } \\
\text { visuoespacial e } \\
\text { atenção; executivo } \\
\text { central }\end{array}$ \\
\hline $\begin{array}{l}\text { Dominó } \\
\text { Divisão }\end{array}$ & $\begin{array}{c}\text { Encontrar o } \\
\text { resultado da } \\
\text { divisão indicada }\end{array}$ & $\begin{array}{l}\text { Treinar habilidade } \\
\text { de atenção, } \\
\text { memória, } \\
\text { pensamento lógico }\end{array}$ & $\begin{array}{c}\text { Atenção } \\
\text { difusa, atenção } \\
\text { concentrada, } \\
\text { memória } \\
\text { de trabalho, } \\
\text { raciocínio lógico }\end{array}$ & $\begin{array}{l}\text { Dominó feito } \\
\text { em papel-cartão, } \\
\text { (adaptado para } \\
\text { idade e ano } \\
\text { escolar) }\end{array}$ & $\begin{array}{c}\text { Memória } \\
\text { visuoespacial e } \\
\text { atenção; executivo } \\
\text { central }\end{array}$ \\
\hline $\begin{array}{l}\text { Jogo de } \\
\text { memória }\end{array}$ & $\begin{array}{c}\text { Combinar pares } \\
\text { com figuras } \\
\text { e palavras } \\
\text { substantivas }\end{array}$ & $\begin{array}{c}\text { Treinar a } \\
\text { habilidade de } \\
\text { atenção, memória, } \\
\text { viso espacial, } \\
\text { flexibilidade } \\
\text { cognitiva }\end{array}$ & $\begin{array}{c}\text { Atenção } \\
\text { concentrada, } \\
\text { memória } \\
\text { de trabalho, } \\
\text { visuoespacial, } \\
\text { flexibilidade } \\
\text { cognitiva }\end{array}$ & $\begin{array}{l}\text { Figuras e seus } \\
\text { nomes em papel- } \\
\text { cartão para formar } \\
\text { pares }\end{array}$ & $\begin{array}{c}\text { Memória } \\
\text { visuoespacial, } \\
\text { circuito } \\
\text { fonológico; } \\
\text { executivo central }\end{array}$ \\
\hline $\begin{array}{l}\text { Jogo de } \\
\text { memória }\end{array}$ & $\begin{array}{l}\text { Combinar figuras } \\
\text { aleatórias }\end{array}$ & $\begin{array}{c}\text { Treinar a } \\
\text { habilidade de } \\
\text { atenção, memória, } \\
\text { visuoespacial, } \\
\text { flexibilidade } \\
\text { cognitiva }\end{array}$ & $\begin{array}{l}\text { Atenção } \\
\text { concentrada, } \\
\text { memória } \\
\text { de trabalho, } \\
\text { visuoespacial, } \\
\text { flexibilidade } \\
\text { cognitiva }\end{array}$ & $\begin{array}{l}\text { Pares de figuras } \\
\text { em papel cartão. }\end{array}$ & $\begin{array}{c}\text { Memória } \\
\text { visuoespacial; } \\
\text { executivo central. }\end{array}$ \\
\hline $\begin{array}{l}\text { Jogo de } \\
\text { memória }\end{array}$ & $\begin{array}{c}\text { Combinar figuras } \\
\text { com masculino e } \\
\text { feminino }\end{array}$ & $\begin{array}{c}\text { Treinar a } \\
\text { habilidade de } \\
\text { atenção, memória, } \\
\text { visuoespacial, } \\
\text { flexibilidade } \\
\text { cognitiva }\end{array}$ & $\begin{array}{c}\text { Atenção } \\
\text { concentrada, } \\
\text { memória } \\
\text { de trabalho, } \\
\text { visuoespacial, } \\
\text { flexibilidade } \\
\text { cognitiva }\end{array}$ & $\begin{array}{c}\text { Figuras de } \\
\text { animais indicando } \\
\text { o "gênero" macho } \\
\text { e fêmea; em papel }\end{array}$ & $\begin{array}{c}\text { Memória } \\
\text { visuoespacial, } \\
\text { circuito } \\
\text { fonológico; } \\
\text { executivo central }\end{array}$ \\
\hline
\end{tabular}




\begin{tabular}{|c|c|c|c|c|c|}
\hline $\begin{array}{c}\text { Quebra } \\
\text { Cabeça } 01\end{array}$ & $\begin{array}{l}\text { Montar a figura } \\
\text { apresentada } \\
\text { através do } \\
\text { encaixe de partes } \\
\text { específicas }\end{array}$ & $\begin{array}{l}\text { Treinar habilidade } \\
\text { de atenção, } \\
\text { memória, } \\
\text { visuoespacial }\end{array}$ & $\begin{array}{c}\text { Atenção } \\
\text { difusa, atenção } \\
\text { concentrada, } \\
\text { memória } \\
\text { de trabalho, } \\
\text { visuoespacial }\end{array}$ & $\begin{array}{l}\text { Quebra-cabeça } \\
\text { feito em papel }\end{array}$ & $\begin{array}{c}\text { Memória } \\
\text { visuoespacial; } \\
\text { executivo central }\end{array}$ \\
\hline $\begin{array}{c}\text { Quebra } \\
\text { Cabeça } 02\end{array}$ & $\begin{array}{l}\text { Montar a figura } \\
\text { apresentada } \\
\text { através do } \\
\text { encaixe de partes } \\
\text { específicas }\end{array}$ & $\begin{array}{c}\text { Treinar habilidade } \\
\text { de atenção } \\
\text { e memória } \\
\text { visuoespacial. }\end{array}$ & $\begin{array}{c}\text { Atenção } \\
\text { difusa, atenção } \\
\text { concentrada, } \\
\text { memória de } \\
\text { trabalho e } \\
\text { visuoespacial. }\end{array}$ & $\begin{array}{l}\text { Quebra-cabeça } \\
\text { feito em papel, } \\
\text { (diferente do } \\
\text { anterior) }\end{array}$ & $\begin{array}{c}\text { Memória } \\
\text { visuoespacial; } \\
\text { executivo central }\end{array}$ \\
\hline $\begin{array}{c}\text { Jogo palavra } \\
\text { escondida }\end{array}$ & $\begin{array}{c}\text { Montar uma } \\
\text { série de palavras } \\
\text { entre letras } \\
\text { distratoras }\end{array}$ & $\begin{array}{l}\text { Treinar habilidade } \\
\text { de atenção e } \\
\text { memória }\end{array}$ & $\begin{array}{c}\text { Atenção } \\
\text { difusa, atenção } \\
\text { concentrada, } \\
\text { memória de } \\
\text { trabalho }\end{array}$ & $\begin{array}{c}\text { Letras e sílabas } \\
\text { impressas em } \\
\text { papel e recortadas }\end{array}$ & $\begin{array}{c}\text { Memória } \\
\text { visuoespacial, } \\
\text { circuito } \\
\text { fonológico; } \\
\text { executivo central }\end{array}$ \\
\hline $\begin{array}{l}\text { Jogo do mico } \\
\text { de sílabas }\end{array}$ & $\begin{array}{l}\text { Montar palavras } \\
\text { a partir da } \\
\text { organização de } \\
\text { cartelas }\end{array}$ & \begin{tabular}{|c} 
Desenvolver a \\
percepção da \\
sílaba como uma \\
das unidades de \\
formação das \\
palavras e melhorar \\
a capacidade de \\
compor e segmentar \\
palavras
\end{tabular} & $\begin{array}{l}\text { Atenção } \\
\text { difusa, atenção } \\
\text { concentrada, } \\
\text { memória de } \\
\text { trabalho }\end{array}$ & $\begin{array}{l}\text { Sílabas impressas } \\
\text { em cartelas que, } \\
\text { combinadas, } \\
\text { formam } \\
\text { substantivos com } \\
\text { a imagem do } \\
\text { referente também } \\
\text { impressa em papel }\end{array}$ & $\begin{array}{c}\text { Memória } \\
\text { visuoespacial, } \\
\text { circuito } \\
\text { fonológico; } \\
\text { executivo central }\end{array}$ \\
\hline $\begin{array}{c}\text { Jogo quebra } \\
\text { palavras }\end{array}$ & $\begin{array}{l}\text { Montar e } \\
\text { segmentar } \\
\text { palavras }\end{array}$ & $\begin{array}{c}\text { O principal objetivo } \\
\text { é desenvolver } \\
\text { a consciência } \\
\text { fonológica, de } \\
\text { modo que o } \\
\text { participante seja } \\
\text { capaz de manipular } \\
\text { fonemas de forma } \\
\text { consciente, saiba } \\
\text { compor palavras } \\
\text { pelas pistas dadas }\end{array}$ & $\begin{array}{l}\text { Memória } \\
\text { fonológica, } \\
\text { circuito } \\
\text { fonológico, } \\
\text { memória } \\
\text { visuoespacial e } \\
\text { atenção }\end{array}$ & $\begin{array}{c}\text { Este jogo é } \\
\text { composto por } \\
35 \text { palavras } \\
\text { segmentadas em } \\
\text { letras que formam } \\
140 \text { tiras. } \\
\text { Combinadas, } \\
\text { formam, além } \\
\text { de palavras, uma } \\
\text { paisagem como } \\
\text { plano de fundo. } \\
\text { Em papel }\end{array}$ & $\begin{array}{c}\text { Memória } \\
\text { visuoespacial, } \\
\text { circuito } \\
\text { fonológico; } \\
\text { executivo central }\end{array}$ \\
\hline $\begin{array}{l}\text { Jogo das } \\
\text { rimas }\end{array}$ & $\begin{array}{l}\text { Combinar } \\
\text { palavras com } \\
\text { rimas }\end{array}$ & $\begin{array}{c}\text { Reconhecer } \\
\text { palavras que } \\
\text { finalizam com } \\
\text { o mesmo som, } \\
\text { saber emparelhar } \\
\text { palavras que } \\
\text { finalizam com o } \\
\text { mesmo som }\end{array}$ & $\begin{array}{l}\text { Memória } \\
\text { fonológica, } \\
\text { circuito } \\
\text { fonológico, } \\
\text { memória } \\
\text { visuoespacial e } \\
\text { atenção }\end{array}$ & $\begin{array}{c}\text { O jogo é } \\
\text { composto por } \\
45 \text { peças que } \\
\text { formam, a cada } 3 \\
\text { peças, um cenário. } \\
\text { Impressas em } \\
\text { papel }\end{array}$ & $\begin{array}{c}\text { Memória } \\
\text { visuoespacial, } \\
\text { circuito } \\
\text { fonológico, } \\
\text { executivo central }\end{array}$ \\
\hline $\begin{array}{c}\text { Jogo } \\
\text { alfabético } \\
\text { silábico }\end{array}$ & $\begin{array}{c}\text { Formar palavras } \\
\text { e frases }\end{array}$ & $\begin{array}{l}\text { Formar palavras, } \\
\text { formar encontros } \\
\text { vocálicos, formar } \\
\text { pequenas frases } \\
\text { reconhecendo as } \\
\text { palavras }\end{array}$ & $\begin{array}{c}\text { Memória } \\
\text { fonológica, } \\
\text { circuito } \\
\text { fonológico, } \\
\text { memória } \\
\text { visuoespacial e } \\
\text { atenção }\end{array}$ & $\begin{array}{c}\text { Letras impressas } \\
\text { em papel e } \\
\text { recortadas }\end{array}$ & $\begin{array}{c}\text { Memória } \\
\text { visuoespacial, } \\
\text { circuito } \\
\text { fonológico; } \\
\text { executivo central }\end{array}$ \\
\hline
\end{tabular}




\begin{tabular}{cc|c|c|c|c} 
& \multicolumn{1}{c|}{$\begin{array}{c}\text { Combinar } \\
\text { bandeiras com } \\
\text { Jomo das } \\
\text { bandeiras } \\
\text { correspondente }\end{array}$} & $\begin{array}{c}\text { Treinar habilidades } \\
\text { de atenção e } \\
\text { memória }\end{array}$ & $\begin{array}{c}\text { Atenção } \\
\text { difusa, atenção } \\
\text { concentrada, } \\
\text { memória de } \\
\text { trabalho }\end{array}$ & $\begin{array}{c}\text { Bandeira dos } \\
\text { estados brasileiros } \\
\text { e o nome dos } \\
\text { estados impressos } \\
\text { em cartelas de } \\
\text { papel }\end{array}$ & $\begin{array}{c}\text { Memória } \\
\text { visuoespacial, } \\
\text { circuito } \\
\text { fonológico; } \\
\text { executivo central }\end{array}$ \\
$\begin{array}{c}\text { Jogo da lista } \\
\text { de super- } \\
\text { mercado }\end{array}$ & Ouvir palavras & $\begin{array}{c}\text { Treinar habilidades } \\
\text { de atenção e } \\
\text { memória }\end{array}$ & $\begin{array}{c}\text { Atenção } \\
\text { difusa, atenção } \\
\text { concentrada, } \\
\text { memória de } \\
\text { trabalho }\end{array}$ & $\begin{array}{c}\text { Atividade oral, } \\
\text { não há material } \\
\text { específico }\end{array}$ & $\begin{array}{c}\text { Memória } \\
\text { visuoespacial, } \\
\text { circuito } \\
\text { fonológico; } \\
\text { executivo central }\end{array}$ \\
\hline
\end{tabular}

Fonte: Mascarello (2016). Protocolo de intervenção com características e domínios mencionados.

\section{TABELA 02 - Realização do protocolo de intervenção}

\begin{tabular}{|c|c|c|c|c|c|}
\hline Atividade & 1a sessão & 2ª sessão & 3a sessão & $4^{a}$ sessão & $5^{a}$ sessão \\
\hline $1^{\mathrm{a}}$ semana & $\begin{array}{c}\text { Dominó }+ \\
\text { Dominó adição }\end{array}$ & $\begin{array}{c}\text { Dominó }+ \\
\text { Dominó adição }\end{array}$ & $\begin{array}{c}\text { Dominó }+ \\
\text { Dominó adição }\end{array}$ & $\begin{array}{c}\text { Dominó }+ \\
\text { Dominó adição }\end{array}$ & $\begin{array}{c}\text { Dominó }+ \\
\text { Dominó adição }\end{array}$ \\
\hline $2^{\mathrm{a}}$ semana & $\begin{array}{c}\text { Figuras e palavras } \\
\text { (substantivos) }+ \\
\text { Jogo dos pares } 1 \\
\end{array}$ & $\begin{array}{c}\text { Figuras e palavras } \\
\text { (substantivos) }+ \\
\text { Jogo dos pares } 1 \\
\end{array}$ & $\begin{array}{c}\text { Figuras e palavras } \\
\text { (substantivos) }+ \\
\text { Jogo dos pares } 1 \\
\end{array}$ & $\begin{array}{c}\text { Figuras e palavras } \\
\text { (substantivos) }+ \\
\text { Jogo dos pares } 1 \\
\end{array}$ & $\begin{array}{c}\text { Figuras e palavras } \\
\text { (substantivos) }+ \\
\text { Jogo dos pares } 1 \\
\end{array}$ \\
\hline $3^{a}$ semana & $\begin{array}{l}\text { Figuras e palavras } \\
\text { (masc/fem) }+ \\
\text { Quebra-cabeça } 2\end{array}$ & $\begin{array}{c}\text { Figuras e palavras } \\
\text { (masc/fem) }+ \\
\text { Quebra-cabeça } 2 \\
\end{array}$ & $\begin{array}{c}\text { Figuras e palavras } \\
\text { (masc/fem) }+ \\
\text { Quebra-cabeça } 2\end{array}$ & $\begin{array}{c}\text { Figuras e palavras } \\
\text { (masc/fem) }+ \\
\text { Quebra-cabeça } 2\end{array}$ & $\begin{array}{l}\text { Figuras e palavras } \\
\text { (masc/fem) }+ \\
\text { Quebra-cabeça } 2\end{array}$ \\
\hline $4^{\mathrm{a}}$ semana & $\begin{array}{l}\text { Quebra-cabeça } 1 \\
\text { Jogo dos pares } 2\end{array}$ & $\begin{array}{l}\text { Quebra-cabeça } 1 \\
\text { Jogo dos pares } 2\end{array}$ & $\begin{array}{l}\text { Quebra-cabeça } 1 \\
\text { Jogo dos pares } 2\end{array}$ & $\begin{array}{l}\text { Quebra-cabeça } 1 \\
\text { Jogo dos pares } 2\end{array}$ & $\begin{array}{l}\text { Quebra-cabeça } 1 \\
\text { Jogo dos pares } 2\end{array}$ \\
\hline $5^{\mathrm{a}}$ semana & $\begin{array}{l}\text { Jogo palavra } \\
\text { escondida }+ \\
\text { Jogo do mico } \\
\end{array}$ & $\begin{array}{l}\text { Jogo palavra } \\
\text { escondida }+ \\
\text { Jogo do mico } \\
\end{array}$ & $\begin{array}{l}\text { Jogo palavra } \\
\text { escondida }+ \\
\text { Jogo do mico } \\
\end{array}$ & $\begin{array}{l}\text { Jogo palavra } \\
\text { escondida }+ \\
\text { Jogo do mico } \\
\end{array}$ & $\begin{array}{l}\text { Jogo palavra } \\
\text { escondida }+ \\
\text { Jogo do mico } \\
\end{array}$ \\
\hline $6^{\mathrm{a}}$ semana & $\begin{array}{c}\text { Jogo quebra } \\
\text { palavras }+ \\
\text { Jogo das rimas }\end{array}$ & $\begin{array}{c}\text { Jogo quebra } \\
\text { palavras }+ \\
\text { Jogo das rimas }\end{array}$ & $\begin{array}{c}\text { Jogo quebra } \\
\text { palavras }+ \\
\text { Jogo das rimas }\end{array}$ & $\begin{array}{c}\text { Jogo quebra } \\
\text { palavras }+ \\
\text { Jogo das rimas }\end{array}$ & $\begin{array}{c}\text { Jogo quebra } \\
\text { palavras }+ \\
\text { Jogo das rimas }\end{array}$ \\
\hline 7a semana & $\begin{array}{c}\text { Jogo alfabeto } \\
\text { silábico }+ \\
\text { Dominó divisão }\end{array}$ & $\begin{array}{c}\text { Jogo alfabeto } \\
\text { silábico+ } \\
\text { Dominó divisão }\end{array}$ & $\begin{array}{c}\text { Jogo alfabeto } \\
\text { silábico+ } \\
\text { Dominó divisão }\end{array}$ & $\begin{array}{c}\text { Jogo alfabeto } \\
\text { silábico }+ \\
\text { Dominó divisão }\end{array}$ & $\begin{array}{c}\text { Jogo alfabeto } \\
\text { silábico }+ \\
\text { Dominó divisão }\end{array}$ \\
\hline $8^{a}$ semana & $\begin{array}{c}\text { Jogo das bandeiras }+ \\
\text { Pares } 1 \\
\end{array}$ & $\begin{array}{c}\text { Jogo das bandeiras }+ \\
\text { Pares } 1\end{array}$ & \begin{tabular}{|c|} 
Jogo das bandeiras + \\
Pares 1 \\
\end{tabular} & \begin{tabular}{|c|} 
Jogo das bandeiras + \\
Pares 1 \\
\end{tabular} & $\begin{array}{c}\text { Jogo das bandeiras }+ \\
\text { Pares } 1 \\
\end{array}$ \\
\hline $9^{\mathrm{a}}$ semana & $\begin{array}{c}\text { Dominó } \\
\text { multiplicação + } \\
\text { Pares } 2 \\
\end{array}$ & $\begin{array}{c}\text { Dominó } \\
\text { multiplicação + } \\
\text { Pares } 2 \\
\end{array}$ & $\begin{array}{c}\text { Dominó } \\
\text { multiplicação + } \\
\text { Pares } 2 \\
\end{array}$ & $\begin{array}{c}\text { Dominó } \\
\text { multiplicação + } \\
\text { Pares } 2 \\
\end{array}$ & $\begin{array}{c}\text { Dominó } \\
\text { multiplicação + } \\
\text { Pares 2 } \\
\end{array}$ \\
\hline $10^{\mathrm{a}}$ semana & $\begin{array}{c}\text { Dominó subtração }+ \\
\text { Lista de } \\
\text { supermercado }\end{array}$ & $\begin{array}{c}\text { Dominó subtração }+ \\
\text { Lista de } \\
\text { supermercado }\end{array}$ & $\begin{array}{c}\text { Dominó subtração }+ \\
\text { Lista de } \\
\text { supermercado }\end{array}$ & $\begin{array}{c}\text { Dominó subtração }+ \\
\text { Lista de } \\
\text { supermercado }\end{array}$ & $\begin{array}{c}\text { Dominó subtração + } \\
\text { Lista de } \\
\text { supermercado }\end{array}$ \\
\hline
\end{tabular}

Fonte: Mascarello (2016). Protocolo de Intervenção. 


\subsection{Análise dos dados}

Para a análise e o tratamento dos dados foram utilizados dois programas de estatística, SPSS e STATISTICA. Do pacote estatístico SPSS (Statistical Package for Social Sciences) foi usada sua versão de número 20, e do STATISTICA foi usada sua versão 8.0.

Após a elaboração dos histogramas, foram utilizados os testes de normalidade de Kolmogorov-Smirnov (K-S) e Shapiro-Wilk (S-W ou W). Os testes fornecem o valor de prova (valor-p, p-value ou significância), indicando a medida de grau de concordância entre os dados e a hipótese nula Ho correspondente à distribuição normal. Quanto menor o valor-p, menor a consistência entre os dados e a hipótese nula.

Foi também utilizado um teste paramétrico, $t$ (T-tests) de comparação múltipla para amostras de grupos emparelhados, além do Newman-Keuls, teste para medidas repetidas. Utilizou-se também a correção de Bonferroni (Fisher-Bonferroni) para diminuir a taxa de erro do grupo dos testes aplicados a fim de verificar a significância estatística das diferenças entre essas medidas dos grupos testados.

Os dados foram submetidos, ainda, a uma análise de variância (ANOVA), Student-Newman-Keuls a,b para verificar se existe uma diferença significativa entre as médias dos dados dos grupos experimental e controle em cada teste, pré-testes e pós-testes. Foi também aplicado o teste Repeated Measures Analysis of Variance with Effect Sizes and Powers, Newman-Keuls test do GLM (modelo linear geral) para medidas repetidas. O GLM segue os mesmos padrões de uma análise de variância. O nível de significância, ou valor $p$, preestabelecido é de $5 \%, p=0,05$.

\section{Resultados e discussão}

Os quadros 01 e 02 exprimem os resultados gerais obtidos pelos participantes da pesquisa sem discriminar os grupos a que pertencem. A tabela 01, por sua vez, apresenta os resultados de desempenho de cada subgrupo dos participantes em que MT indica a memória de trabalho (três sub testes) e TCLPP indica os resultados dos testes de leitura (sete sub testes). 
QUADRO 01 - Resultados gerais obtidos da aplicação dos pré-testes

\begin{tabular}{|c|c|c|c|c|c|c|c|}
\hline \multirow{2}{*}{ Variável } & \multicolumn{7}{|c|}{ Todos os grupos - Estatística descritiva pré-teste } \\
\cline { 2 - 8 } & № válido & Média & Mediana & Mínimo & Máximo & $\begin{array}{c}\text { Desvio } \\
\text { padrão }\end{array}$ & $\begin{array}{c}\text { Erro } \\
\text { padrão }\end{array}$ \\
\hline WM DG $^{1}$ & 165 & 8,32 & 9,00 & 1,00 & 18,00 & 2,70 & 0,21 \\
\hline WM SNL & 165 & 8,79 & 9,00 & 1,00 & 17,00 & 2,89 & 0,23 \\
\hline WM AR & 165 & 6,83 & 7,00 & 1,00 & 16,00 & 2,63 & 0,20 \\
\hline TCLPP total & 165 & 88,06 & 84,69 & 37,61 & 122,03 & 16,61 & 1,29 \\
\hline Leitura CR & 165 & 95,39 & 101,80 & 24,86 & 111,42 & 17,14 & 1,33 \\
\hline Leitura CI & 165 & 95,23 & 94,53 & 0,00 & 117,09 & 17,29 & 1,35 \\
\hline Leitura VS & 165 & 87,93 & 89,69 & 0,00 & 108,74 & 21,22 & 1,65 \\
\hline Leitura VV & 165 & 91,02 & 92,52 & 0,00 & 113,12 & 19,13 & 1,49 \\
\hline Leitura VF & 165 & 88,32 & 88,35 & 0,00 & 119,45 & 20,30 & 1,58 \\
\hline Leitura PH & 165 & 80,77 & 85,12 & 0,00 & 123,35 & 29,01 & 2,26 \\
\hline Leitura PE & 165 & 97,20 & 97,20 & 0,00 & 108,01 & 24,78 & 1,91 \\
\hline
\end{tabular}

Fonte: Mascarello (2016, p.119).

${ }^{6} \mathrm{WM}=$ memória de trabalho; $\mathrm{DG}=$ Teste Dígitos (pontuação, mínima 0, máxima 32 pontos); $\mathrm{SNL}=$ teste sequência de números e letras (pontuação, mínima 0 , máxima 30 pontos); $\mathrm{AR}=$ teste aritmética (pontuação, mínima 0 , máxima 34 pontos); TCLPP = teste de compreensão e leitura de palavras e pseudopalavras (pontuação obtida a partir de 01 a 70 acertos); $\mathrm{CR}=$ teste de palavras corretas regulares (pontuação obtida a partir de 01 a 10 acertos); CI - = teste de palavras corretas irregulares (pontuação obtida a partir de 01 a 10 acertos); VS = teste de palavras vizinha semânticas (pontuação obtida a partir de 01 a 10 acertos); $\mathrm{VV}=$ teste de palavras vizinhas visuais (pontuação obtida a partir de 01 a 10 acertos); $\mathrm{VF}=$ teste de palavras vizinhas fonológicas (pontuação obtida a partir de 01 a 10 acertos); $\mathrm{PH}=$ teste de pseudopalavras homófonas (pontuação obtida a partir de 01 a 10 acertos); $\mathrm{PE}=$ teste de pseudopalavras estranhas (pontuação obtida a partir de 01 a 10 acertos). A pontuação dos testes de leitura, seja o TCLPP total sejam os subtestes, referem-se à pontuação padrão, que, para o segundo ano do Ensino Fundamental e para a média de idade do grupo, poderiam variar entre 11,63 e 123,65 pontos (no caso de zero é porque não houve nenhum acerto). 
QUADRO 02 - Resultados gerais obtidos na aplicação dos pós-testes

\begin{tabular}{|c|c|c|c|c|c|c|c|}
\hline \multirow{2}{*}{ Variável } & \multicolumn{7}{|c|}{ Todos os grupos - Estatística descritiva pós-teste } \\
\cline { 2 - 8 } & № válido & Média & Mediana & Mínimo & Máximo & $\begin{array}{c}\text { Desvio } \\
\text { padrão }\end{array}$ & $\begin{array}{c}\text { Erro } \\
\text { padrão }\end{array}$ \\
\hline WM DG & 165 & 9,20 & 9,00 & 1,00 & 19,00 & 2,85 & 0,22 \\
\hline WM SNL & 165 & 10,05 & 10,00 & 4,00 & 18,00 & 2,43 & 0,19 \\
\hline WM AR & 165 & 8,07 & 8,00 & 2,00 & 18,00 & 2,75 & 0,21 \\
\hline TCLPP total & 165 & 98,81 & 100,92 & 34,36 & 123,65 & 15,26 & 1,19 \\
\hline Leitura CR & 165 & 103,67 & 111,42 & 44,10 & 111,42 & 11,38 & 0,89 \\
\hline Leitura CI & 165 & 103,24 & 109,57 & 56,94 & 117,09 & 12,97 & 1,01 \\
\hline Leitura VS & 165 & 97,17 & 99,21 & 0,00 & 108,74 & 16,16 & 1,26 \\
\hline Leitura VV & 165 & 98,62 & 106,25 & 0,00 & 113,12 & 16,03 & 1,25 \\
\hline Leitura VF & 165 & 96,52 & 94,57 & 0,00 & 119,45 & 17,12 & 1,33 \\
\hline Leitura PH & 165 & 92,85 & 90,87 & 0,00 & 123,35 & 19,99 & 1,56 \\
\hline Leitura PE & 165 & 99,69 & 108,01 & 0,00 & 108,01 & 15,59 & 1,21 \\
\hline
\end{tabular}

Fonte: Mascarello (2016, p. 120).

TABELA 03 - Resultados comparados, média de desempenho

\begin{tabular}{cc|c|c|c}
\hline \multirow{2}{*}{ Grupo } & \multicolumn{1}{c}{$\begin{array}{c}\text { MT } \\
\text { (Pré-teste) }\end{array}$} & \multicolumn{2}{c}{$\begin{array}{c}\text { MT } \\
\text { (Pós-teste) }\end{array}$} & \multicolumn{2}{c}{$\begin{array}{c}\text { TCLPP } \\
\text { (Pré-teste) }\end{array}$} & \multicolumn{1}{c}{$\begin{array}{c}\text { TCLPP } \\
\text { (Pós-teste) }\end{array}$} \\
\hline Experimental & 5,83 & 8,44 & 70,03 & 96,23 \\
\cline { 2 - 5 } Controle & 5,43 & 6,21 & 67,25 & 76,11 \\
\cline { 2 - 5 } Regular & 10,36 & 10,88 & 101,79 & 107,61 \\
\hline WmpobreLn & 7,33 & 8,94 & 98,45 & 100,8 \\
\hline LpobreWMn & 8,72 & 9,11 & 79,6 & 98,9 \\
\hline
\end{tabular}

Fonte: Mascarello (2016, p. 167). ${ }^{7}$

A padronização dos testes de memória de trabalho afirma que valores mais próximos de 5 pontos indicam baixos índices dessa

${ }^{7} \mathrm{O}$ texto completo da tese com mais informações sobre os dados e com todos os resultados pode ser encontrado no site: $<$ https://repositorio.ufsc.br/handle/12345678 9/169205? show $=$ full $>$ 
memória e próximos de 10 pontos indica normalidade de desempenho nessa memória, quanto mais altos os índices mais próximos do conceito de superdotação (indivíduos com alta capacidade) e quanto mais baixos indicam incapacidade para preservação e operacionalização da informação.

Em relação a padronização dos testes de leitura, abaixo de 84 pontos indica baixa capacidade para leitura e reconhecimento de palavras escritas (para o ano escolar e a idade dos sujeitos). Acima de 84 pontos e quanto mais próximos de 123 pontos indica desenvolvimento normal (aceito como adequado) para escolaridade e idade.

Podemos observar na tabela 01 que de um modo geral todos os grupos apresentaram alguma alteração (para mais) nos valores dos pós testes, entretanto, destacamos os resultados obtidos pelos grupos Experimental e Controle. Esses grupos apresentaram um resultado baixo nos testes de memória de trabalho nos pré-testes: o grupo Experimental alcançou uma média de 5,83 e o grupo Controle 5,43 e, por consequência, baixo desempenho nos testes de leitura de palavras, 70,03 e 67,25 respectivamente.

Ao observar os resultados, outra constatação é que os participantes que obtiveram os melhores índices gerais nos testes que avaliaram a MT, grupo Regular com 10,88 pontos também apresentaram os melhores resultados nos testes que avaliaram o desempenho geral em leitura 101,79 pontos no TCLPP e em todos os subtestes de leitura.

Segundo Gathercole e Alloway (2008, p.15), "a memória de trabalho atua como uma ponte temporária entre as ações externas e as representações mentais geradas internamente nos indivíduos". ${ }^{8}$

Considera-se que entre os elementos cognitivos, a memória de trabalho pode servir como um indicador de desempenho, em especial do desempenho escolar das crianças. Mascarello (2016, p. 52) relata que "tanto os estudos de Baddeley $(1996,2000)$ Baddeley et al. (2011) quanto os de Gathercole e Alloway (2008) e Dehn (2008) mostram que a aprendizagem depende de uma boa memória de trabalho." Outras pesquisas, tais como, Alloway et al. (2006), Dollaghan et al. (1997) e Weismer et al. (2000), entre outros, afirmam que a partir da avaliação da memória de trabalho é possível identificar qual é o potencial ou a capacidade de aprendizagem de uma criança.

Ao pesquisar crianças em idade escolar, aplicando testes em três grupos, sendo um grupo com idade entre 6 e 7 anos, outro entre

\footnotetext{
${ }^{8}$ Working memory [...] and that acts as a temporary bridge between externally and internally generated mental representations. Tradução do autor.
} 
10 e 11 anos e o terceiro, adolescentes entre 13 e 14 anos, Gathercole e Alloway (2008), aplicando testes de memória de trabalho e avaliando o desempenho escolar desses mesmos estudantes nas disciplinas de leitura, matemática e ciências, as pesquisadoras perceberam que as crianças que obtiveram baixos índices nos testes de memória de trabalho apresentavam também baixos rendimentos na escola.

O maior desafio enfrentado em sala de aula pelos estudantes que apresentam baixos índices na memória de trabalho, segundo Gathercole e Alloway (2008), é manter ativas na mente as informações suficientes que lhes permitam completar tarefas. Essa falta de manutenção ocasiona perdas de informações cruciais e provoca esquecimento de vários aspectos importantes, como as instruções que estão tentando seguir, os detalhes do que eles estão fazendo, o passo a passo de uma tarefa difícil de forma adequada e assim por diante. Quando ocorre uma interrupção no processamento, o único caminho possível, segundo Gathercole e Alloway (2006), é começar de novo o processo de entrada de informação na memória de trabalho.

Para Just e Carpenter (1992), pesquisadores que iniciaram os estudos sobre as diferenças individuais, defendem a tese de que a compreensão da linguagem de uma pessoa depende de sua capacidade de memória e da constituição da sua individualidade, os sujeitos não agem da mesma forma diante de todos os fatos linguísticos. Para Gathercole e Alloway (2006), além das reações e das diferenças individuais, defendem também que a memória de trabalho não é igual em todas as pessoas, e que o limite dos índices da memória de trabalho não é idêntico em indivíduos da mesma idade, as experiências pessoais e as características individuais podem interferir na memória de trabalho, sendo que cada indivíduo tem uma capacidade relativamente fixa, que pode ser maior ou menor do que a dos outros. Assim, uma determinada atividade pode ser bem executada por um indivíduo, isto é, está de acordo com a capacidade de uma pessoa, mas superior à do outro. Segundo Daneman e Carpenter (1980) e, posteriormente, Gathercole, Lamont e Alloway (2006), os processos de memória de trabalho revelam diferenças individuais na capacidade de aprendizagem. A memória de trabalho será sempre ativada e necessária quando se deve aprender qualquer informação nova, pois aprendizagem requer manipulação de informação e armazenamento simultâneo dessas novas informações processadas.

Os resultados dos dados da pesquisa são condizentes e corroboram com a literatura e pesquisas anteriores em que crianças que apresentaram 
menor índice na memória de trabalho também apresentaram menor desempenho em leitura e reconhecimento de palavras. A partir dos resultados encontrados, parece evidente que quanto mais baixos os índices de memória de trabalho, maior é a dificuldade de aprendizagem dos processos de leitura. Com os índices pobres em memória de trabalho, o desempenho em leitura é afetado de tal modo que interfere nos processos mais básicos, como a decodificação e a diferenciação dos traços das letras.

Outro aspecto constatado é que a partir da intervenção realizada com o grupo experimental os resultados dos índices melhoraram consideravelmente aproximando-se do grupo Regular, passando de 5,83 pontos para 8,44. À medida que o grupo Experimental melhorou os índices de MT, melhorou também os índices do TCLPP passando de 70,03 para 96,23, o que indica que passaram de baixa capacidade de leitura de palavras para capacidade normal, isto é, adequada para ano escolar e idade (diferença estatisticamente significativa). Uma pequena melhora também foi observada nos outros grupos. A diferença da melhora dos outros grupos é considerada uma melhora natural do desenvolvimento infantil (GATHERCOLE et al., 2008), entretanto, tal alteração não foi identificada como estatisticamente significativa. O grupo Controle, que não foi submetido ao experimento interventivo continuou apresentando muitas dificuldades. Os índices de MT continuaram baixos (de 5,43 para 6,21 ) e as dificuldades em leitura persistiram passando de 67,25 para 76,11 , ainda abaixo do mínimo de 84 pontos, ou seja, não alcançaram os índices satisfatórios e necessários para o ano escolar e a idade.

Ao analisar os dados observa-se a confirmação de que a MT tem papel crucial e relevante para a aprendizagem de leitura. Os resultados dos dados obtidos nessa pesquisa são consonantes com os resultados das pesquisas de Daneman e Merikle (1996). Ao tratar de MT e habilidade de compreensão da linguagem os pesquisadores verificaram que crianças com menores índices na MT apresentavam mais dificuldades de compreensão.

Um dos primeiros e principais estudos da área de avaliação de MT e leitura de Daneman e Carpenter (1980) mostrou que a MT, além de ser de alta importância para a aprendizagem e compreensão de leitura, apresenta variação entre os indivíduos. Esse fato tem sido demonstrado por uma série de estudos subsequentes (ENGLE, KANE, TUHOLSKI, 1999; JUST, CARPENTER, 1980, 1992). Mais de uma década depois Gathercole e Alloway (2006) defendem e sustentam mesmo ponto de vista. Ademais, as autoras defendem também que a capacidade de MT pode aumentar naturalmente com o avanço da idade durante a infância até o final da adolescência. 
Em Mascarello (2016, p. 168), lemos:

Estudos que avaliam habilidades cognitivas, como as baterias de testes cognitivos, como WISC-IV (2013), também apontam relação entre memória de trabalho e decodificação de leitura, compreensão de leitura, compreensão da linguagem, desenvolvimento vocabular, expressão escrita. Além do WISC-IV, pode-se observar em testes de Engle (1996); Engle, Kane, Tholski (1999); Gathercole, Alloway (2008), que defendem o mesmo ponto de vista sobre o tema referido. Como colocado, segundo esse enfoque, indivíduos com maior capacidade de memória de trabalho seriam mais aptos a desenvolver determinadas atividades propostas no cotidiano escolar ou fora da escola.

Acreditamos que ao aperfeiçoar a MT, aperfeiçoa-se a capacidade de gerir a realidade, permitindo que se preste mais atenção ao ambiente em nosso entorno, à ocorrência dos fatos e ao tipo de informação que circula no tempo e no espaço em que nos encontramos. Todavia, como não é atribuição da MT gerar inventários para serem guardados, mas sim conservar de maneira consciente informações necessárias para que ocorra 0 entendimento da continuidade do texto (oral ou escrito). E, principalmente, porque tanto a medida quanto a intervenção para melhorar a MT são promovidas por ações indiretas, já que, segundo Izquierdo (2011, p. 26) “[...] a MT não é acompanhada por alterações bioquímicas [...] seu breve processamento parece depender da atividade elétrica dos neurônios do córtex pré-frontal". Por essa razão, não queremos generalizar e categorizar que a melhoria de todos os índices dos resultados do grupo Experimental ocorreu exclusivamente pelo protocolo de intervenção executado, ainda que os resultados estatísticos mostrem uma estreita relação entre tais eventos.

\section{Considerações finais}

O propósito central pretendido com este estudo, é contribuir com o debate que vem sendo travado em território nacional sobre os diferentes aspectos possíveis de serem analisados no ato de ler. Pretendemos também com esta pesquisa fornecer dados e ampliar a argumentação referente aos diferentes posicionamentos teóricos demandados e suscitados em decorrência dos diversos entendimentos do que é leitura e o papel da MT no desenvolvimento da habilidade de ler. Estamos cientes de que a leitura 
"é objeto de conhecimento e também fonte, isto é, instrumento necessário para ampliar o conhecimento e meio de aprendizagem. $O$ processo de aprendizagem de leitura é um processo interativo (leitor x texto), mas não um processo simples, pois para qualquer ato de leitura é necessário pelo menos um objetivo, uma meta que coloque o leitor em movimento, em outras palavras, toda leitura tem uma finalidade" (MASCARELLO, 2016, p. 182).

Tal movimento demanda, entre outras coisas, uma capacidade de controle e autocontrole para que ao ler algo se tenha êxito (que o objetivo proposto seja alcançado sendo ele qual for). $\mathrm{O}$ controle e o autocontrole advêm e relacionam-se à aprendizagem de regras básicas da escrita e de domínio dos aspectos grafemo-fonológicos, além de outros conhecimentos necessários que garantam o êxito da realização do ato de ler, evitando, assim, o desespero advindo do não conhecimento mínimo que garanta a inserção no universo das letras.

A partir dos métodos adotados e dos testes estatísticos aplicados para a análise dos resultados dos testes de MT e de leitura silenciosa de palavras e pseudopalavras dos sujeitos indivíduos colaboradores da pesquisa, ficou evidente que há uma estreita relação entre a capacidade de MT e o desempenho em leitura de palavras e pseudopalavras. De acordo com o argumentado e apresentado nos resultados e na análise de dados, percebe-se que os sujeitos que obtiveram resultados considerados normais nos testes de MT obtiveram também os melhores índices nos resultados dos testes de leitura de palavras e pseudopalavras, e, por sua vez, os sujeitos com índices mais baixos nos testes de MT apresentaram um pior resultado nos testes de leitura de palavras e pseudopalavras. Aferiu-se também que quanto mais baixos os índices de desempenho em MT, mais altas as dificuldades e menores os índices nos testes de leitura de palavra e pseudopalavras. Em virtude dessas indicações, entendemos que, para esse grupo pesquisado, e com as metodologias adotadas para a realização do estudo, a MT é um elemento ou componente cognitivo indispensável para o sucesso na aprendizagem de leitura. Os resultados obtidos nesta pesquisa não parecem resultados isolados, mas, ao contrário, corroboram os resultados de outras pesquisas (apresentados na revisão de literatura e na discussão dos resultados).

Diante disso, defendemos que existe relação entre MT e aprendizagem de leitura e as hipóteses apresentadas no início do estudo foram confirmadas pelos dados, bem como as respostas obtidas pela 
análise dos dados às perguntas postas foram satisfatórias. Sem embargo, o espaço delegado e delimitado para estudos cognitivos, neurocognitivos e neurocientíficos na maioria das escolas brasileiras ainda é escasso, é necessário ainda percorrer um longo caminho para que se amplie e se aprofunde a discussão sobre todos os aspectos dessa relação.

\section{Referências}

ALLOWAY, Tracy P.; GATHERCOLE, Susan E.; PICKERING, Susan J. Verbal and Visuospatial Short-Term and Working Memory in Children: Are They Separable? Child Development, [s.1.], v. 77, n. 6, p. 1698-1716, Nov./Dec. 2006. Doi: https://doi.org/10.1111/j.1467-8624.2006.00968.x

ATKINSON, Richard; SHIFFRIN, Richard. Human Memory: A Proposed System and Its Control Processes. In: SPENCE, K.; SPENCE, J. T. (Ed.). The Psychology of Learning and Motivation. 2. ed. New York: Academic Press, 1968. Cap. 2. p. 89-195.

BADDELEY, A. D.; HITCH, G. J. Working Memory. In: BOWER, G. H. (Ed.). The Psychology of Learning and Motivation. New York: Academic Press, 1974. v. 8, p. 47-89.

BADDELEY, Alan. Working Memory: Looking Back and Looking Forward. Nature Reviews Neuroscience, [s.1.], v. 4, p. 829-839, 2003.

BADDELEY, Alan. The Episodic Buffer: a New Component of Working Memory? Trends in Cognitive Sciences, [s.1.], v. 4, n. 11, p . 417-423, 2000.

BADDELEY, Alan. Your Memory: A User's Guide. 3. ed. London: Prion Books, 1996.

BADDELEY, Alan. Working Memory. Science, [s.1.], v. 255, p. 556-559, Jan. 1992.

BADDELEY, Alan; ANDERSON, Michael C.; EYSENCK, Michael. Memória. Tradução de Cornélia Stolting. Porto Alegre: Artemed, 2011.

BARKLEY, Russell A.; BENTON, Christine. Vencendo o TDAH adulto. Porto Alegre: Artmed, 2011.

CAPOVILLA, Fernando C.; CAPOVILLA, Alessandra Gatuzo S.; MACEDO, Elizeu. Recursos de reabilitação de distúrbios da comunicação e linguagem para melhor qualidade de vida em quadros sensoriais, motores e cognitivos. O Mundo da Saúde, São Paulo, v. 30, n. 1, p. 26-36, 2006. 
CAPOVILlA, Alessandra Gatuzo S.; CAPOVILlA, Fernando C.; MACEDO, Elizeu. Funções executivas em crianças e correlação com desatenção e hiperatividade. Temas sobre Desenvolvimento, São Paulo, v. 14, n. 82 , p. 4-14, 2005.

DANEMAN, Meredyth; MERIKLE, Philip M. Working Memory and Language Comprehension: A Meta Analysis. Psychonomic Bulletin \& Review, [s.1.], v. 3, n. 4, p. 422-433, 1996.

DANEMAN, Meredyth; CARPENTER, Patricia A. Individual Differences in Working Memory and Reading. Journal of Verbal Learning and Verbal Behavior, [s.1.], v. 19, n. 4, p. 450-466, 1980. Doi: https://doi. org/10.1016/S0022-5371(80)90312-6

DEHN Milton. Working Memory and Academic Learning. Assessment and Intervention. Canadá: John Wiley, 2008.

DOLLAGHAN, Chris et al. Reducing Bias in Language Assessment: A Processing-Dependent Measure. Journal of Speech, Language and Hearing Research, [s.1.], v. 40, p. 519-525, 1997.

ENGLE, Randall W. Working Memory and Retrieval: An InhibitionResource Approach. In: RICHARDSON, John T. E.; ENGLES, Randall W.; HASHER, Lynn; LOGIE, Robert H.; STOLTZFUS, Ellen R.; ZACKS, Rose T. Working Memory and Human Cognition. New York: Oxford University Press, 1996. p. 89-119. Doi: DOI:10.1093/acprof:o so/9780195100990.003.0004

ENGLE, Randall W.; KANE, Michael J.; TUHOLSKI Stephen W. Individual Differences in Working Memory Capacity and What They Tell Us About Controlled Attention, General Fluid Intelligence, and Functions of the Prefrontal Cortex. In: MYAKE, Akira; SHAH, Priti (Ed.). Models of Working Memory. Mechanisms of Active Maintenance and Executive Control. Cambridge: Cambridge University Press, 1999. p. 102-134.

GATHERCOLE, Susan E.; ALLOWAY, Tracy P. Working Memory and Learning: A Practical Guide. London: Sage Press, 2008.

GATHERCOLE, Susan E.; ALLOWAY, Tracy P. Working memory and classroom learning. University of Durham: Elsevier, 2006.

GATHERCOLE, Susan E.; LAMONT, Emily; ALLOWAY, Tracy P. Working memory in the classroom. In: PICKERING Susan (Org.). Working Memory and Education. Amsterdam: Elsevier, 2006. p. 219-240. 
GATHERCOLE, Susan E.; DURLING, Emily; EVANS, Matthew; JEFFCOCK, Sarah; STONE, Sarah. Working Memory Abilities and Children's Performance in Laboratory Analogues of Classroom Activities. Applied Cognitive Psychology, [s.1.], v. 22, p. 1019-1037, 2008.

GATHERCOLE, Susan E.; PICKERING, Susan J. Assessment of Working Memory in Six-and Seven-Year-Old Children. Journal of Educational Psychology, [s.1.], v. 92, p. 377-390, 2000.

GOUGH, Philip B. One Second of Reading. In: SINGER, Henry; RUDDELL, Robert B. (Org). Theoretical Models and Processes of Reading. 2. ed. New York: International Reading Association, 1976. p. 509-535.

HOLMES, Joni; GATHERCOLE, Susan E.; DUNNING, Darren L. Adaptive Training Leads to Sustained Enhancement of Poor Working Memory in Children. Developmental Science, [s.1.], v. 12, n. 4, p. 9-15, 2009. Doi: 10.1111/j.1467-7687.2009.00848.x.

IZQUIERDO, Ivan. Memória. 2. ed. Porto Alegre: ArtMed, 2011.

JUST, Marcel Adam; CARPENTER, Patricia A. The Capacity Theory of Comprehension: Individual Differences in Working Memory. Psychological Review, [s.1.], v. 99, n. 1, p. 122-149, 1992.

KANDEL, Eric R. Em busca da memória: o nascimento de uma nova ciência da mente. São Paulo: Companhia das Letras, 2009.

KLINGBERG, Torkel et al. Computerized Training of Working Memory in Children with ADHD - a Randomized, Controlled Trial. Journal American Academy Child and Adolescent. Psychiatry, [s.1.], v. 44, n. 2, p. 177-186, 2005. Doi: 10.1097/00004583-200502000-00010

KLINGBERG, Torkel et al. Increased Brain Activity in Frontal and Parietal Cortex Underlies the Development of Visuo-Spatial Working Memory Capacity During Childhood. Journal Cognitive Neuroscience, [s.1.], v. 14, n. 1, p. 1-10, 2002. Doi: https://doi.org/10.1162/089892902317205276

MASCARELLO, Lidiomar José. Memória de trabalho e desempenho em leitura: um estudo com crianças do ensino fundamental. 2016. Tese (Doutorado em Linguística) - Universidade Federal de Santa Catarina, Florianópolis, 2016.

PURVES Dale; AUGUSTINE George J.; FITZPATRICK, David; HALL, William C.; LAMANTIA, Anthony-Samuel; MCNAMARA, James O.; 
WILLIAMS, Mark S. Neuroscience. 3. ed. Sunderland, MA: Sinauer Associates, 2004.

LEFFA, Vilson. J. Aspectos da leitura: uma perspectiva psicolinguística. Porto Alegre: Sagra-DC Luzzatto, 1996. 105p.

SCLIAR-CABRAL, Leonor; SOUZA, Ana Claudia. Língua portuguesa e ensino: alfabetização para o letramento e desenvolvimento da leitura. In: SOUZA, Ana Claudia; OTTO, Clarícia; FARIAS, Andressa da Costa (Org.). A escola contemporânea: uma necessária reinvenção. Florianópolis: NUP/CED, 2011. 179 p.

SEABRA, Alessandra Gotuzo; CAPOVILLA, Fernando César. Teste de competência de leitura de palavras e pseudopalavras: (TCLPP). São Paulo: Memnon, 2010.

SHIPSTEAD, Zach; REDICK, Thomas S.; ENGLE, Randall W. Does Working Memory Training Generalize? Psychologica Belgica, Georgia, n. 50 , v. 3, p. $245-276,2010$.

SOUZA, Ana Claudia; GARCIA, Wladimir Antonio Costa. A produção de sentidos e o leitor: os caminhos da memória. Florianópolis: NUP/ CED/UFSC, 2012.

SOUZA, Ana Cláudia de. Leitura, metáfora e memória de trabalho: três eixos imbricados. 2004. Tese (Doutorado em Linguística) - Universidade Federal de Santa Catarina, Florianópolis, 2004.

SWANSON, H. Lee; SACHSE-LEE, Carole. Mathematical Problem Solving and Working Memory in Children with Learning Disabilities: Both Executive and Phonological Processes Are Important. Journal of Experimental Child Psychology, v.79, n. 3, p. 294-321, 2001. Doi: 10.1006/jecp.2000.2587

WECHSLER David. A Escala Wechsler de Inteligência para Crianças WISC-IV. Adaptação Brasileira de Fabián Javier Marín Rueda, Ana Paula Porto Noronha, Fermino Fernandes Sisto, Acácia Aparecida Angeli dos Santos, Nelimar Ribeiro de Castro. São Paulo: Casa do Psicólogo, 2013.

WEISMER, Susan Ellis et al. Nonword repetition Performance in SchoolAge Children with and Without Language Impairment. Journal of Speech, Language, and Hearing Research, [s.1.], v. 43, p. 865-878, 2000. Doi: 10.1044/jslhr.4304.865 